\title{
Experimental quantification of 3D deformations in sensitive clay during stress-probing
}

\author{
GEORGIOS BIRMPILIS*, EDWARD ANDÒ†, OLGA STAMATI†, STEPHEN A. HALL ${ }^{\S}$, \\ ELENI GEROLYMATOU"l" and JELKE DIJKSTRA ${ }^{\|}$
}

\begin{abstract}
Unique four-dimensional (4D) deformation data are collected during drained triaxial tests on intact specimens of a natural sensitive clay. This requires the development of a miniature triaxial cell for advanced stress path testing, specifically designed for X-ray computed tomography. Salient features include the omission of a membrane, and a mounting procedure that minimises disturbance by the experimenter. Three distinct drained stress ratios are studied for pseudo-isotropic, $K_{0}$, and highly deviatoric loading paths. The results indicate that the $K_{0}$ path shows the most uniform deformation mechanism, where the measured ratio of deviatoric and volumetric strain increments reach the stress ratio applied at boundary value level for large magnitudes of total strain. The pseudo-isotropic test also reaches a strain ratio close to $\eta$ at large total strain levels; however, the deformation field is less uniform. Furthermore, the highly deviatoric stress path shows the most heterogeneous deformation fields commensurate with the applied stress ratio, although the ratio of deviatoric and volumetric strain increments falls above the $\eta$ applied. The mean value of the three-dimensional spatial fields of strain corresponds well with the changes observed at boundary level, supporting prior research on drained stress-probing on clays for which there are no 4D deformation data available.
\end{abstract}

KEYWORDS: clays; micro-CT tomography; strain; stress path testing; triaxial tests

\section{INTRODUCTION}

Natural sensitive clays exhibit a complex non-linear response under coupled hydro-mechanical loading in, for example, oedometric and triaxial tests (Burland, 1990; Smith et al., 1992; Karstunen \& Koskinen, 2008). The physico-chemical processes, which originate from the colloidal nature of the clay particles and govern the formation of natural clays, affect the deformation response of the material observed at engineering scale. In the geotechnical literature for structured soils, all these factors are strongly associated with processes at the microscale that evolve during coupled hydro-mechanical loading (e.g. Burland, 1990; Leroueil \& Vaughan, 1990; Cotecchia \& Chandler, 1997; Wheeler et al., 2003; Amorosi \& Rampello, 2007; Karstunen \& Koskinen, 2008). The compressibility and strength characteristics of natural clays are

Manuscript received 19 May 2021; revised manuscript accepted 26 November 2021.

Discussion on this paper is welcomed by the editor.

Published with permission by the ICE under the CC-BY 4.0 license. (http://creativecommons.org/licenses/by/4.0/)

* Department of Architecture and Civil Engineering, Chalmers University of Technology, Sven Hultins, Gothenburg, Sweden (Orcid:0000-0002-8353-693X).

$\dagger$ EPFL Center for Imaging, École Polytechnique Fédérale de Lausanne (EPFL), EPFL IMAGING, Lausanne, Switzerland; also University of Grenoble Alpes, CNRS, Grenoble INP, Grenoble, France (Orcid:0000-0001-5509-5287).

† CNRS, Grenoble INP, Universite Grenoble Alpes, Grenoble, France (Orcid:0000-0002-7492-2134).

$\S$ Division of Solid Mechanics, Lund University, Lund, Sweden; also

Lund Institute of Advanced Neutron and X-ray Science, Lund, Sweden (Orcid:0000-0002-5232-4942).

|| Technical University Clausthal, Clausthal-Zellerfeld, Germany (Orcid:0000-0003-1279-6870).

I Chalmers University of Technology, Department of Architecture and Civil Engineering, Sven Hultins, Gothenburg, Sweden

(Orcid:0000-0003-3792-0727). controlled by the irreversible change of the assembly and the interaction between the clay platelets and particles (Hicher et al., 2000). Sensitive clays by definition exhibit significant post-peak softening: the high ratio between the strength in the undisturbed state and the ultimate state, or otherwise the remoulded state at the same water content - that is, the sensitivity - can reach values in excess of 50 for quick clays. Quick clays are characterised by well-graded particle distributions of chemically active and inactive particles from sub-micrometres $(\mu \mathrm{m})$ to millimetres $(\mathrm{mm})$ (Cabrera \& Smalley, 1973). In addition to clay minerals, a large number of inert particles (rock flour) are present in the clay and the silt fraction of the material (Brand \& Brenner, 1981).

Macroscopic studies of the hydro-mechanical response of fine-grained soils have sometimes been complemented by microstructural investigations. In addition to studies on reconstituted and natural clays (e.g. Burland, 1990; Cotecchia \& Chandler, 1997), studies on pure clay, such as reconstituted kaolin, or clay mixtures have been used as a proxy for natural clays (Diamond, 1970; Hattab et al., 2015). The use of reconstituted kaolin clay enables the control of the stress history for a material whose physico-chemical composition and microstructure are well characterised, and have been tested extensively in other materials sciences (e.g. Ma \& Eggleton, 1999). For example, Martin \& Ladd (1975) and Anandarajah et al. (1996) investigated the role of the microstructure and mechanical response of kaolin clay using, respectively, X-ray diffraction and electron micrographs.

The first efforts to correlate the evolution of the microstructure of mechanical behaviour in natural clays used a combination of electron microscopy and X-ray diffraction (XRD) (Pusch, 1966; Quigley \& Thompson, 1966; Martin \& Ladd, 1975). Pusch (1966) studied the effect of shearing (unconfined compression) on samples of Swedish quick clay using electron microscopy. This required substitution of the pore water with acrylic plastic to enhance the contrast and to stabilise the sample. Delage \& Lefebvre (1984) employed scanning electron microscopy (SEM) and mercury intrusion 
porosimetry (MIP) to study the effect of consolidation on intact, remoulded and reconstituted Canadian sensitive clays. Since the seminal work of Delage \& Lefebvre (1984), electron microscopy and MIP have greatly contributed to revealing the evolving microstructure of artificial and natural clays before and after mechanical perturbation (Lapierre et al., 1990; Tanaka \& Locat, 1999; Mitaritonna et al., 2014; Cotecchia et al., 2019). Hattab and her co-workers (Hattab \& Fleureau, 2010; Hattab et al., 2013) studied the evolution of the fabric orientation in relation to stress history for, respectively, reconstituted kaolin and reconstituted natural clays. These methods require potentially invasive preparation techniques, which can produce artefacts such as a volume change and result in microscopic structures that are not representative of the material in its natural state (Quigley \& Thompson, 1966; Deirieh, 2016; Deirieh et al., 2018). Nevertheless, potential disturbance can be minimised significantly with appropriate sample preparation and testing procedures (Delage \& Pellerin, 1984; Menaceur et al., 2016). Birmpilis et al. (2019) monitored the nanoscale fabric evolution of undisturbed sensitive clay in its natural state during compression using small angle X-ray scattering (SAXS). Observations of the evolution of the orientation and the d-spacing of particles of different mineralogy were quantified during continuous loading. SAXS, however, has limitations on the size of the features that can be measured, and an integrated response of all material along the X-ray beam passing through the sample is obtained, in a similar fashion to transmission electron microscopy. An alternative approach to microstructural observations is to infer the effect of microstructure on the macroscopic response by altering the composition of the pore-water chemistry (Pedrotti \& Tarantino, 2018). Subsequently, knowledge of the particlelevel interactions (as a function of pore-water chemistry) was linked with microscale and macroscale observations and modelling. Finally, the effect of fabric and anisotropy has been inferred by comparing the experimental response of reconstituted and intact samples of natural clay at continuum scale (e.g. Wheeler et al., 2003; Karstunen \& Koskinen, 2008).

In recent years, significant advances have been made on X-ray imaging techniques for the observation of deformation and fabric evolution in geomaterials. After the first experiments that used radiographs to study density changes in plane-strain problems (e.g. Arthur, 1962; Roscoe et al., 1963), Kirkpatrick \& Belshaw (1968) used X-ray radiography to examine the conditions of strain during a triaxial compression experiment. Desrues et al. (1996) reported the first use of X-ray computed tomography (XCT) for qualitative and quantitative determination of the void ratio evolution and strain localisation during triaxial loading of dry sand. This new approach revolutionised experimental geomechanics, leading to more routine use of in operando testing of geomaterials with XCT imaging (Lenoir et al., 2007; Alshibli \& Hasan, 2008; Hall et al., 2010; Matsushima et al., 2010; Andó et al., 2012). The spatial resolution of XCT still falls short for particle-level observations in fine-grained materials, with clay particles that typically have submicron dimensions. Nevertheless, the difference in the X-ray attenuation between the silt and the clay fraction naturally present in sensitive clays provides the necessary contrast for subsequent digital volume correlation (DVC) analyses of the XCT data (Birmpilis et al., 2017).

Previous experimental efforts for fine-grained materials, although increasing the understanding of the materials studied, have not fully bridged the gap between the particle-level mechanisms and the macroscopic response. Consequently, the available experimental results are too limited for revising the hardening laws in contemporary constitutive models at the continuum scale for natural clays in light of the microstructural evolution. This specifically requires a combination of systematic stress probing (e.g. Al-Tabbaa \& Wood, 1989; Wheeler et al., 2003; Karstunen \& Koskinen, 2008) with simultaneous monitoring of internal deformation mechanisms.

In the present study, X-ray tomography observations are made on intact samples of natural sensitive clay during drained probing over three different controlled stress ratios in the triaxial space in a specially developed triaxial cell. The aim is to investigate the deformation response of a natural clay sample during drained triaxial compression. For different stress ratios the resulting strain uniformity is examined and the ratio of deviatoric to volumetric strain is used as a metric that can be linked to the flow rule. In conducting this research the authors aspire to improve understanding between concurrent particle-scale investigations and macroscale element testing, providing experimental evidence for the mesoscale, and supporting further constitutive model development.

\section{METHODOLOGY}

Miniature triaxial apparatus

A miniature advanced stress path testing triaxial apparatus that is compatible with XCT was developed for the experiments reported herein. The reduction in the sample size by a factor $n$ reduces the field of view required, thus increasing the attainable spatial resolution. Furthermore, the characteristic time for consolidation reduces by $n^{2}$, which enables drained stress-probing of sensitive clay that has low hydraulic conductivity, $O\left(10^{-9} \mathrm{~ms}^{-1}\right)$, in a couple of days rather than weeks. The latter makes the test more compatible with the limited availability of XCT instrument time. The XClay miniature triaxial apparatus (Fig. 1) is designed based on a Bishop-Wesley cell that uses hydraulic pressures regulated with a syringe pump to control the cell pressure,

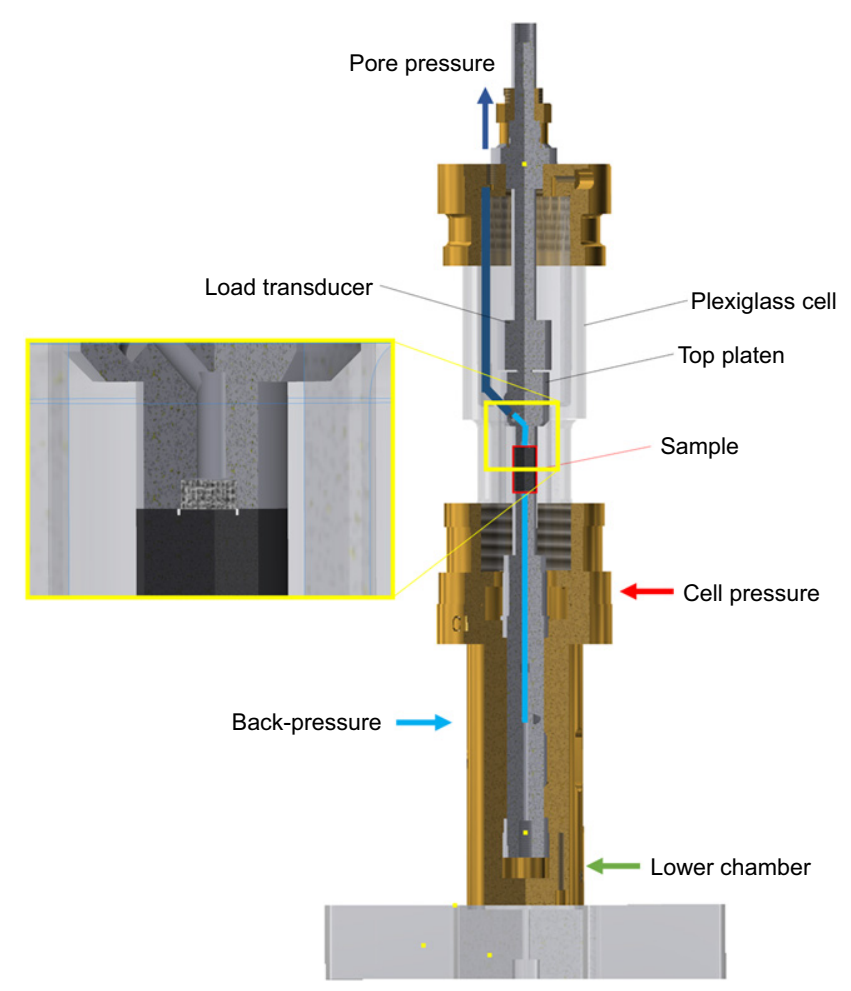

Fig. 1. Three-quarter-section view of the XClay miniature triaxial apparatus (inset focusing on connection between top cap and sample) 
back-pressure and axial stress for the loading piston independently (Bishop \& Wesley, 1975). The apparatus supports both stress and displacement (fluid volume) control on all three pressure lines.

The low stress levels and small size of XClay allows the use of an acrylic cell with $8 \mathrm{~mm}$ wall thickness without reinforcements or tension rods. A reduced inner diameter of the cell is machined at the location of the specimen to minimise the X-ray attenuation from the confining liquid surrounding the sample.

Owing to the small size and the low stiffness of the clay sample, the addition of a membrane is associated with practical difficulties, such as sample disturbance. Therefore, a membrane-less configuration using the paraffin method (Iversen \& Moum, 1974) is used. Paraffin oil (CAS no. $8042-47-5$, dynamic viscosity $110-230 \mathrm{mPa} \mathrm{s}$ at $20^{\circ} \mathrm{C}$ ) is immiscible with the water in the pores of the clay sample and so, in combination with the low permeability of the clay, penetration of the paraffin into the sample does not occur at the pressure levels applied $(<200 \mathrm{kPa})$. Fig. 2 shows a vertical slice of an XCT image of a sample with an iodine-containing non-ionic radiocontrast agent dissolved in the pore water. Clearly, the paraffin oil surrounding the sample does not penetrate the sample, and the radiocontrast agent does not diffuse into the paraffin.

All the hydraulic connections to the pumps and the electrical cables that are connected to the base of the triaxial cell are bundled together into a sufficiently long strand at the base of the rotation stage of the tomograph, to allow for an unrestricted $360^{\circ}$ rotation of the triaxial apparatus during an XCT scan.

To mount a sample of intact natural clay on the pedestal of the XClay device an untouched-by-hand procedure was adopted (Fig. 3). In this method, a stainless steel cutting tube of $10 \mathrm{~mm}$ dia. is pushed into a piston sample collected from the field ( $50 \mathrm{~mm}$ dia.) with a constant penetration rate of $0.6 \mathrm{~mm} / \mathrm{min}$ (Fig. 3(a)).

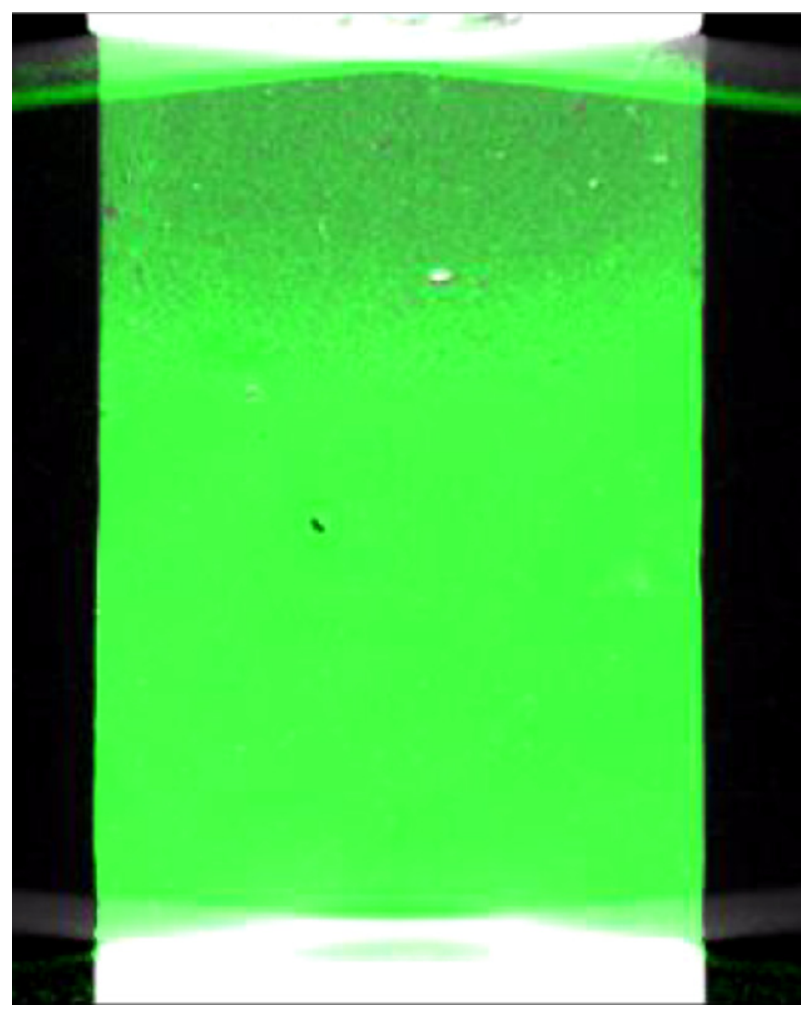

Fig. 2. XCT on a sample with a contrast agent dissolved in the pore water. The paraffin surrounding the sample does not penetrate
The selected penetration rate is a trade-off between generation of excess pore-water pressures from overly fast penetration and undesired drying effects that might result from a prolonged procedure. Subsequently, the cutting tube filled with the miniature sample is cut free from the master sample. Then, the miniature sample is placed on the pedestal of the XClay apparatus by sliding the bottom of the cutting ring, left empty for this purpose, onto the top of the pedestal (Figs 3(b) and 3(c)). In the last step the miniature sample is extruded and aligned by sliding the ring down around the base of the pedestal (Fig. 3(d)). The interface between the miniature sample and the end platens on the pedestal needs to be sealed to prevent the cell liquid from entering the pore-water pressure and back-pressure channels. To seal the interface, a sharp and thin protruding ring - part of the end platen - (height: $0.3 \mathrm{~mm}$; inner diameter: $4 \cdot 2 \mathrm{~mm}$; thickness: $0 \cdot 1 \mathrm{~mm}$ ) surrounding the undersized porous disc penetrated into the sample during mounting. The X-ray radiography in Fig. 4 shows the effectiveness of this solution for the interface between the clay specimen and the top (Fig. 4(a)) and bottom platens (Fig. 4(b)). The quality of the samples was controlled by maintaining constant volume during sampling, and subsequently by inspecting the sample dimensions after mounting and stress application. Furthermore, for the $K_{0}$ loading path, the additional volumetric strain when reaching the in situ stress conditions was negligibly small $\left(\varepsilon_{\mathrm{v}}=1 \cdot 1 \%\right.$; see Fig. 10). This indicates high-quality samples (Lunne et al., 1997).

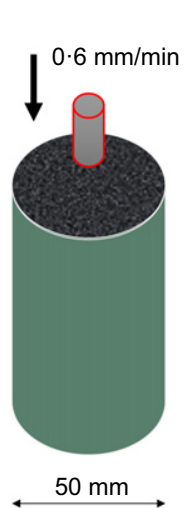

(a)

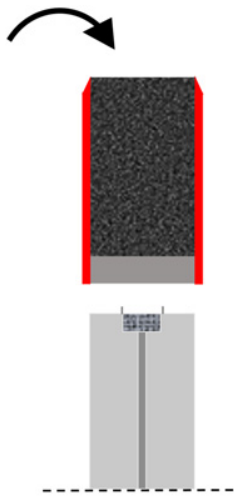

(b)

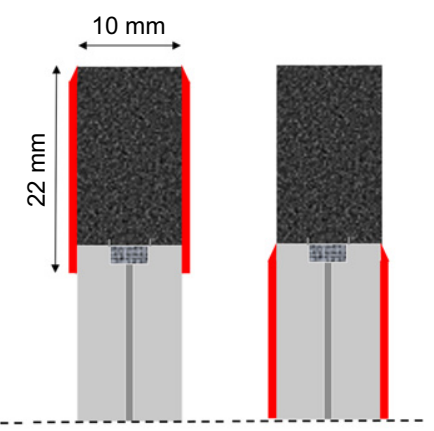

(c)

(d)
Fig. 3. Sampling and mounting procedure for the miniature samples used in XClay triaxial apparatus: (a) cutting ring penetration, (b) subsample cut free from master sample, (c) sample aligned on pedestal and (d) sample mounted on pedestal

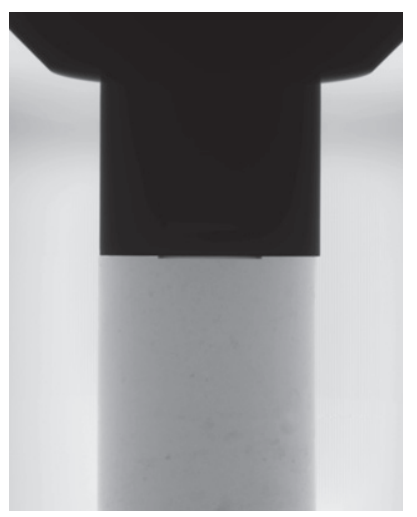

(a)

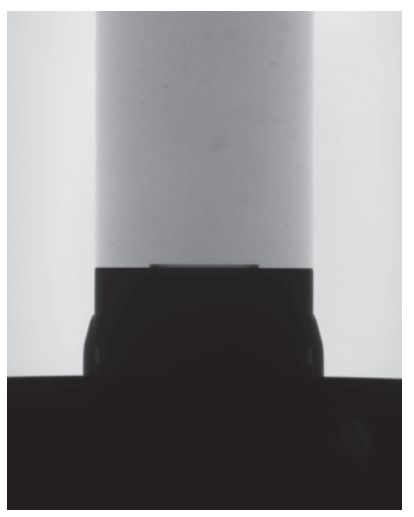

(b)
Fig. 4. X-ray radiography of the details of the connection of the sample with (a) the top and (b) the bottom platen 


\section{Material}

The material tested is a natural sensitive clay of medium sensitivity and high silt content. The $50 \mathrm{~mm}$ Swedish STII piston sampler was used for field sampling from the well-characterised Utby test site in Gothenburg, Sweden (Karlsson et al., 2016; Li et al., 2018; Birmpilis et al., 2019). Samples were retrieved from depths between 5 and $6 \mathrm{~m}$. The index properties of the clay are summarised in Table 1 after Karlsson et al. (2016). The sampled clay is mainly composed of illite and montmorillonite (Birmpilis et al., 2019).

\section{Testing programme}

The test series included effective stress probing at different stress ratios $\eta=q / p^{\prime}$, where in triaxial space the effective stress invariants correspond to $p^{\prime}=(1 / 3)\left(\sigma_{1}^{\prime}+2 \sigma_{3}^{\prime}\right)$ and $q=$ $\left(\sigma_{1}^{\prime}-\sigma_{3}^{\prime}\right)$, respectively, and 'denotes effective stress. The experimental procedure focuses on values for $\eta$ that fall below the critical state line, $M$ - that is, no sample was brought to failure. Large target values for $p_{\text {final }}^{\prime}(2-3$ times larger than the in situ value of $p^{\prime}$ ) were chosen to ensure significant deformations in each test. Furthermore, prior experimental and theoretical work on soft sensitive clays indicate that fabric evolution for structured fine-grained soils becomes substantial when probing extends far beyond the yield point (Wheeler et al., 2003; Karstunen \& Koskinen, 2008). Table 2 presents the three test paths investigated, the number of tomographies acquired and the subsequent DVC settings for processing the results.
A pseudo-isotropic load path with a small additional axial load was chosen over a pure isotropic loading path (controlled by cell pressure only), in order to maintain the seal between the end platens and the sample required for the paraffin method. The highly deviatoric and pseudo-isotropic stress paths are expected to re-arrange the clay fabric for rather extreme stress ratios, while the (expected) $K_{0}$ path continues a consolidation path that should be similar to the in situ consolidation history of the deposit.

\section{$X$-ray computed tomography}

The XCT provides a semi-quantitative three-dimensional (3D) field of the X-ray attenuation of the test specimens, based on the interaction of X-ray photons with electrons in the sample. The X-ray attenuation coefficient depends on the X-ray energy, the atomic number and the density of the material. The spatial contrast in X-ray attenuation for the tested natural sensitive clay results from the difference in attenuation of the silt grains and the clay matrix, which consist of different minerals and particle sizes present in the clay (see the particle size distribution in Fig. 5).

The experiments were conducted in operando in the RX-Solutions X-ray tomograph at Laboratoire 3SR described by Viggiani et al. (2015). Fig. 6 is a photograph of XClay installed in the scanner. Once the field of view had been selected, a trade-off was made between signal-to-noise

Table 1. Soil characterisation: unit density, $\rho$; plastic limit, $w_{\mathrm{p}}$; natural water content, $w_{\mathrm{N}}$; liquid limit, $w_{\mathrm{l}}$; plasticity index (PI); sensitivity, $S_{\mathrm{t}}$; undrained shear strength from fall cone test correlation, $\tau_{\mathrm{fu}}$; and slope of critical state line, $M$, from CAUC triaxial test (Karlsson et al., 2016)

\begin{tabular}{l|c|c|c|c|c|c|c|c}
\hline Depth: $\mathrm{m}$ & $\rho: \mathrm{t} / \mathrm{m}^{3}$ & $w_{\mathrm{p}}: \%$ & $w_{\mathrm{N}}: \%$ & $w_{1}: \%$ & PI: \% & $S_{\mathrm{t}}$ & $\tau_{\mathrm{fu}}: \mathrm{kPa}$ & $M$ \\
\hline 5 & 1.55 & 25 & 81 & 63 & 38 & 30 & 10 & $1 \cdot 5$ \\
6 & 1.59 & 22 & 71 & 55 & 33 & 26 & 9 & $1 \cdot 5$ \\
\hline
\end{tabular}

Table 2. Test overview for the three stress paths (shown in Fig. 7(a)) and their corresponding DVC settings

\begin{tabular}{|c|c|c|c|c|c|c|}
\hline Test & $\eta$ & Scan no. & ns: px & hws: px & DVC analysis & Search range: $\mathrm{px}$ \\
\hline $\begin{array}{l}\text { Aniso } \\
K_{0} \\
\text { Pseudo-iso }\end{array}$ & $\begin{array}{l}0 \cdot 9 \\
0 \cdot 55 \\
0 \cdot 18\end{array}$ & $\begin{array}{l}74 \\
71 \\
67\end{array}$ & $\begin{array}{l}15 \\
15 \\
20\end{array}$ & $\begin{array}{l}15 \\
15 \\
20\end{array}$ & $\begin{array}{l}\text { Previous displ. field + pixel search } \\
\text { Registration + pixel search } \\
\text { Registration + pixel search }\end{array}$ & 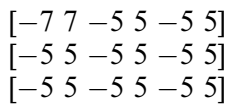 \\
\hline
\end{tabular}

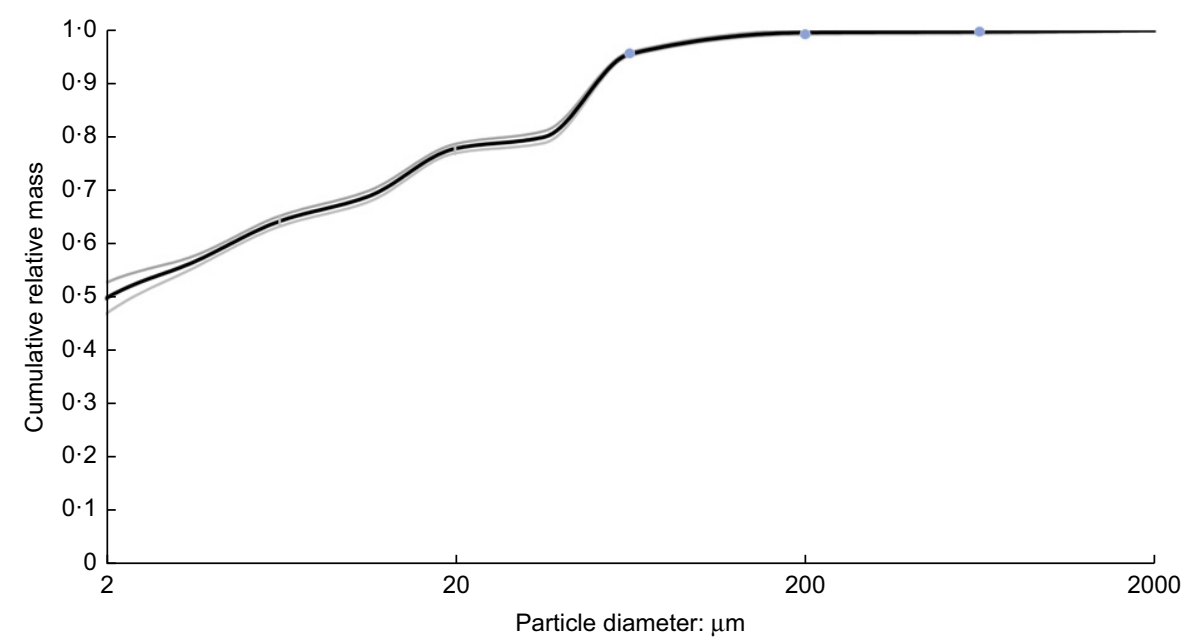

Fig. 5. Particle size distribution for the fine-grained fraction of Utby clay (6 $\mathrm{m}$ depth). The grey lines indicate the uncertainly boundaries of the measurement 


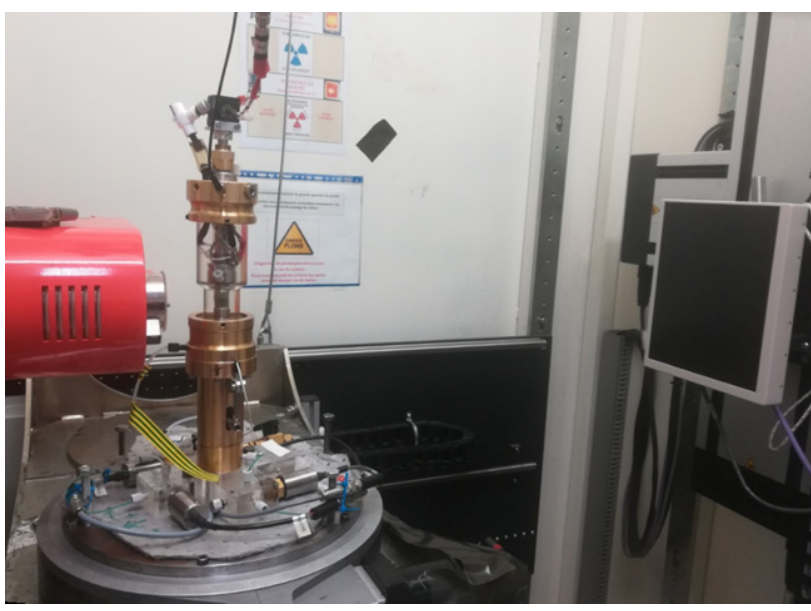

Fig. 6. The XClay miniature triaxial apparatus mounted on the stage of the X-ray scanner of Laboratoire 3SR

ratio, spatial resolution and temporal resolution of the tomographies and the hydromechanical loading rate applied in the triaxial test. A continuous hydro-mechanical loading rate $\left(\Delta q_{\eta=0.90}=54 \mathrm{kPa}, \quad \Delta q_{\eta=0.55}=36 \mathrm{kPa}\right.$, $\Delta q_{\eta=0.18}=10 \mathrm{kPa}$ in $50 \cdot 6 \mathrm{~h}, 47 \cdot 5 \mathrm{~h}$ and $45 \cdot 4 \mathrm{~h}$, respectively) at pre-determined stress ratio $(\eta)$ required a scan time of $21.3 \mathrm{~min}$ to avoid motion artefacts. A $41.7 \mathrm{~min}$ time interval between XCT images was chosen to have sufficient deformation in-between subsequent scans. All these considerations resulted in $3 \mathrm{D}$ scans with a voxel size of $25 \times 25 \times 25 \mu \mathrm{m}$. The voltage and current of the X-ray source were set to $100 \mathrm{kV}$ and $220 \mu \mathrm{A}$ with an exposure time of $2 \mathrm{~s}$ on each radiography. The scanning was performed during a $360^{\circ}$ continuous rotation of the triaxial cell with smooth start and stop ramps during which 640 projections $(728 \times 920$ pixels $)$ were acquired.

\section{Digital volume correlation}

Digital volume correlation is the extension of digital image correlation (DIC) to 3D volume images. Correlation methods compare pairs of images acquired at two different stages of loading (in time) to measure the transformation between the two images. To obtain a spatially resolved field to map one image into another, a persistent fine-scale texture is needed. For images, this can be added to the surface being studied DIC, but for DVC the natural texture is almost always relied upon. Since in this case the voxel size of $25 \mu \mathrm{m}$ is far larger than the finest clay and silt fractions in the natural clay tested, these features were not resolved in the XCT images. However, the larger silt grains offer the texture required, so that mesoscale material displacements can be measured.

Here the spam toolkit (Stamati et al., 2020) is used for DVC, using a local approach, whereby independent cubic subvolumes are defined in the reference image and sought in the deformed image. The correlation core in spam aims to measure a linear deformation function expressed in homogeneous coordinates called $\Phi$, through an iterative procedure, and formulated as a $4 \times 4$ matrix, which can encode displacements, rotations, stretches and shears. The algorithm is based on the approach of Lucas \& Kanade (1981) developed in Hild \& Roux (2012) and Tudisco et al. (2017). The significant volumetric strains that occur in the tested samples pose a number of challenges for DVC measurements, as described below.

(a) The attenuation of the clay matrix increases during the experiments as it compresses, while the (less-attenuating) pore water is expelled. The DVC used in spam considers a classic sum of squared differences for the measure of similarity between images, which is violated by this change in the attenuation of the clay matrix. Consequently, images are pre-processed for DVC: the attenuation of the clay matrix is adjusted using the mean volumetric strain measured in the specimen employing the saturated model presented in Stavropoulou et al. (2020), approximating $\mu^{\text {water }}$ as $\mu^{\text {paraffin }}$

(b) The large amounts of deformation also cause a problem for a total DVC analysis (i.e. measuring deformation using the first pre-deformed image as a reference for each deformed step, as opposed to incremental analysis between consecutive load steps).

This is tackled using a combination of the following approaches.

(a) Perform an initial non-rigid registration of the full sample, which catches the overall average displacement, strain and rotation in a homogeneous $\Phi_{\mathrm{av}}$. Thereafter, an initial estimate of the displacement based on $\Phi_{\mathrm{av}}$ and the position in the sample is applied.

(b) In cases where the initial guess from $\Phi_{\mathrm{av}}$ is not sufficiently close for the sub-volumes to converge (typically expected in the case of significant strain localisation), then a 'pixel search' is executed. The latter operates a raster search of displacements around the guessed displacement for the best correlation. A sub-pixel refinement runs after the pixel search.

(c) In the unique case where the preceding solutions are not sufficient to follow the deformation of the sample all the way through the experiment, the previously measured $\Phi$ can also be used as an initial guess. This is robust, but means that a sub-volume, once lost, cannot be recovered in subsequent increments.

The choices made to have a well-converged field of $\Phi$ for each sub-volume are listed in Table 2; 'ns' indicates the spacing between the measurement nodes, which are kept constant to have similar measurement grids and the same gauge length for the strain between samples, and 'hws' indicates the 'half-window' size, which is the number of voxels in $x ; y ; z$ selected either side of the measurement node to define the sub-volume for correlation. In all cases, there is overlap between neighbouring correlation sub-volumes (of 30\% and $50 \%$ for hws $=15$ and hws $=20$, respectively).

Strains are obtained by extracting only the displacement part of the total fields of $\Phi$ for each sub-volume and computing the transformation gradient tensor $\boldsymbol{F}=$ $I+(\delta u / \delta x)$ on Q8 shape functions linking $2 \times 2 \times 2$ neighbouring measurement points. Polar decomposition of the transformation gradient tensor, $\boldsymbol{F}=\boldsymbol{R} \boldsymbol{U}$, yields the right stretch tensor $\boldsymbol{U}$ and the rotation tensor $\boldsymbol{R}$ for each Q8 element. The finite-strain framework is used to calculate the volumetric, $\varepsilon_{\mathrm{v}}=\operatorname{det}(\boldsymbol{F})-1$, and deviatoric strain, $\varepsilon_{\mathrm{d}}=$ $\left\|\boldsymbol{U}^{\operatorname{dev}}-I\right\| ; \boldsymbol{U}^{\operatorname{dev}}=\operatorname{det}(\boldsymbol{F})^{-(1 / 3) \boldsymbol{U}^{2}}$, components based on a multiplicative decomposition of the stretch tensor $\boldsymbol{U}$ into a pseudo-isotropic and deviatoric part. The strain definition used follows the convention of engineering strain, where positive volumetric strains are compressive.

\section{RESULTS}

Figure 7 presents an overview of the results for three triaxial compression tests on independent samples of the natural sensitive clay. Fig. 7(a) shows the target and measured stress ratios for each test - namely, $\eta_{\text {aniso }}=0.90$; 


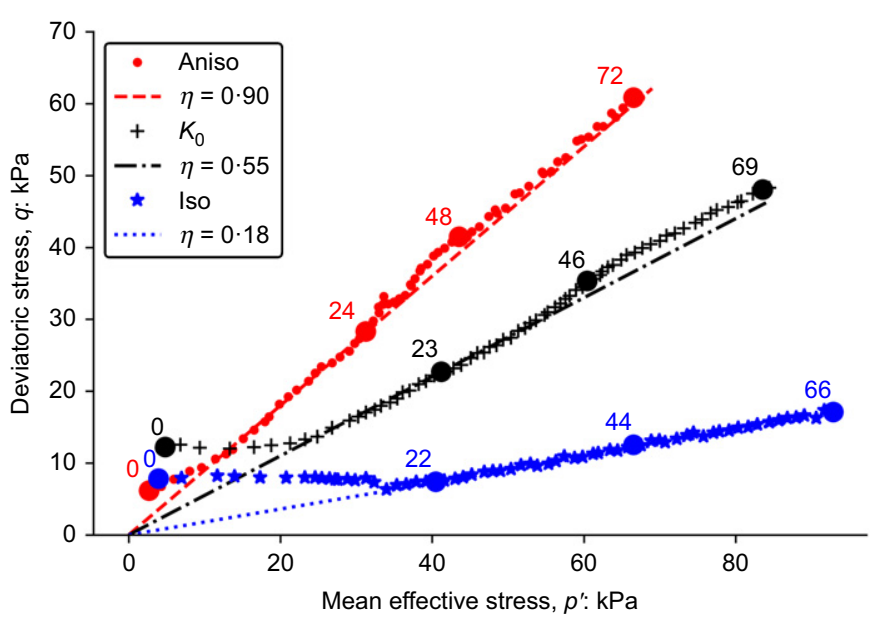

(a)

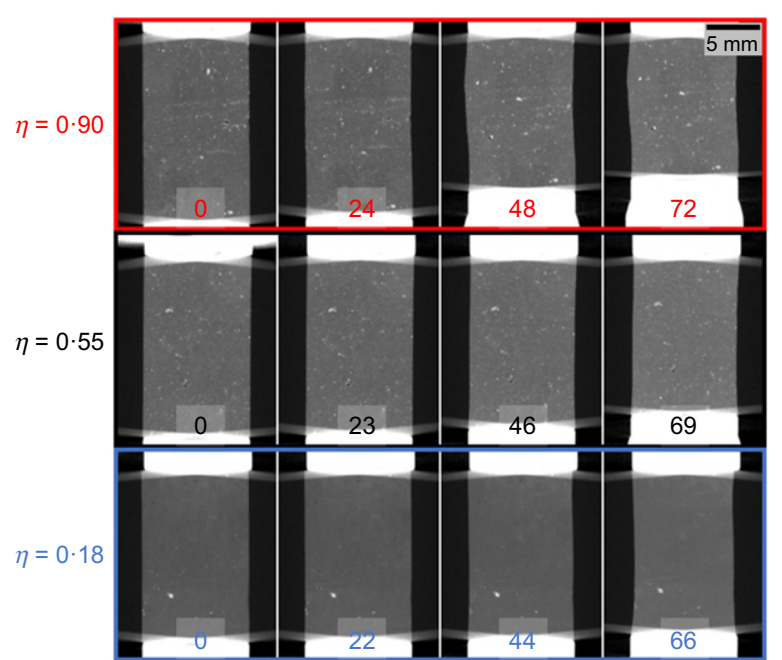

(b)

Fig. 7. (a) Stress paths and (b) the respective mid-sections of the sample in different deformation stages

$\eta_{K_{0}}=0 \cdot 55$; and $\eta_{\text {iso }}=0 \cdot 18$. The tests started with an initial deviatoric stress $(q)$ resulting from the mounting and docking of the sample. Therefore, each test first approached the desired stress path before continuing with a constant $\eta$ up to a final value for $p^{\prime}$, which ensures significant fabric evolution (Wheeler et al., 2003) - that is, $p_{\text {final }}^{\prime}=2 \sim 3 p_{0}^{\prime}$. Fig. 7(b) shows a vertical cross-section through the tomography volumes at the centre of the sample for four instances during each test (marked in Fig. 7(a)), highlighting the differences in deformation mechanisms during each stress path.

The processed strain fields (dimensions: $38 \times 28 \times 28$ elements) for the three tests are presented in Figs 8 and 9 for the deviatoric strain and the volumetric strain, respectively. A median filter with radius 2 pixels was applied to the displacement fields, before calculating the strain fields to reduce the noise. The sample tested with a highly deviatoric stress path, $\eta=0 \cdot 9$, presents higher magnitudes of deviatoric and volumetric strain, as well as indications of the localisation of strains. The samples tested with $\eta=0.55$ and $\eta=0.18$ present a comparable spatial distribution of strain that is rather uniform for both deviatoric and volumetric strain components. The strain fields for the pseudo-isotropic loading path show that the deformations are non-isotropic, as some deviatoric strains are generated. Compared to the two other loading paths, however, the response is still considered most representative for, although not equal to, the isotropic case.

The mean values of the volumetric strain fields (Fig. 9) have been used to determine the yield points for each stress path (Fig. 10), using a bilinear construction in the $p^{\prime}-\varepsilon_{\mathrm{v}}$ space (similar to Karstunen \& Koskinen (2008)). The sample exposed to the highly deviatoric stress path exhibits a yield point much earlier than the other two loading paths. That is to be expected based on critical state soil mechanics. The low magnitude for the yield point is further corroborated by the localisation of shear strains in a band. The stress ratio $\eta=0.9$ of this stress path is close to the critical state line $(M=1 \cdot 5)$, which is likely to result in significant excess pore-water pressures being generated due to high magnitudes of shear strains. Therefore, to prevent premature failure, for this loading path only, the shearing was temporarily halted by holding the total stress constant and allowing the excess pore-water pressures to dissipate.

The evolution of the mean values of the deviatoric and volumetric components of total strain and their standard deviations are plotted for each stress path as functions of time

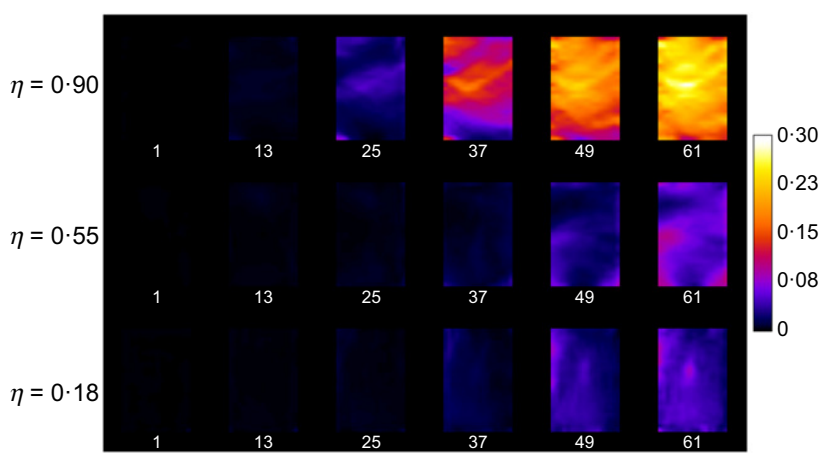

Fig. 8. Spatial field of maximum deviatoric strain for highly deviatoric, $K_{0}$ and pseudo-isotropic stress path

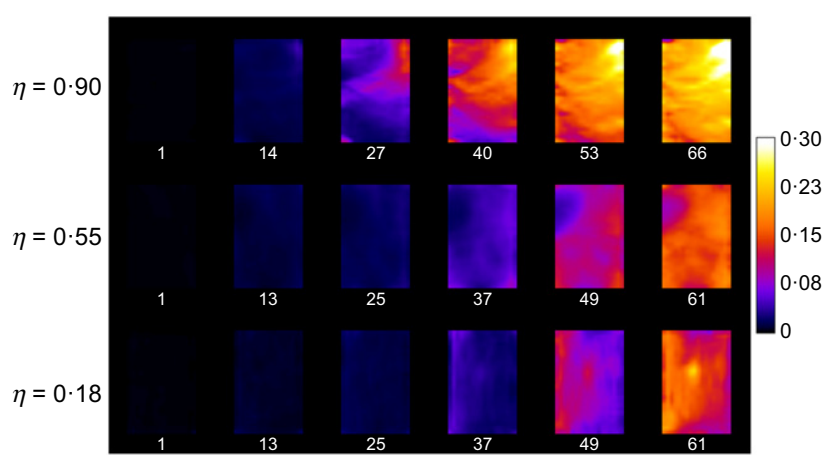

Fig. 9. Spatial field of volumetric strain for highly deviatoric, $K_{0}$ and pseudo-isotropic stress path (compression is positive)

step in the left-hand side of Fig. 11. Each time step represents an XCT scan with an interval of $41.7 \mathrm{~min}$. The ratios of the total volumetric strains and total deviatoric strains derived from the DVC are plotted on the right-hand side of Fig. 11. Points in this space are tinted according to their XCT scan time. This figure represents the statistics from individual strain paths for in excess of 7000 individual points in each sample. These measurements are independent of experimental issues with measuring an axial strain and or change in pore-water volume at the boundary of the sample. Hence, $\mathrm{XCT}$ and DVC shows great merit for quantitative monitoring of the mesoscale processes in terms of non-uniform 


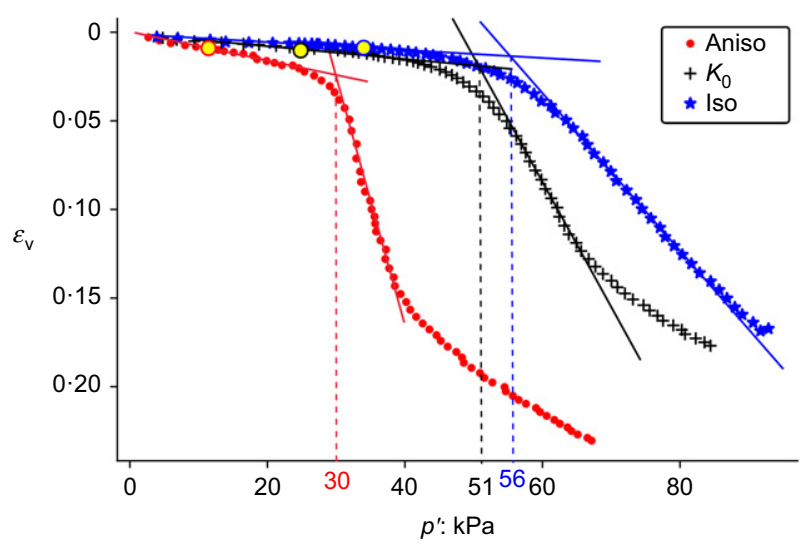

Fig. 10. Determination of yield points for the highly deviatoric, $K_{0}$ and pseudo-isotropic stress path. The highlighted points (circle markers) indicate when the stress path reaches the target stress ratio

deformations and their statistical interpretation in (natural) clay samples during element-level laboratory testing. The total strain cannot be decomposed into elastic and plastic strain components in the absence of a clear onset of yield for each individual point, for which local knowledge of stress is required. Nevertheless, the time-strain data indicate a clear change in gradient associated with the yield, after which the strain magnitudes and spread increase more rapidly, at respectively tomography number 25 (anisotropic), $40\left(K_{0}\right)$ and 30 (pseudo-isotropic). Post-yield, the total strains are expected to be largely dominated by irrecoverable strains. This interpretation is supported by the small magnitude of measured total strain, hence elastic strain, prior to yield. The mean of total strain ratio appears to follow the trend of the stress ratio applied at boundary value level rather well for each point within the sample. Compared to the total strains, the incremental strains are more helpful for discerning the constitutive response during a test. Fig. 12 shows a similar plot to Fig. 11, but for the incremental strains, plus an additional figure for each test shows the time series for the boundary level stress ratio $q / p^{\prime}$ and the ratio of strain increments $\delta \varepsilon_{\mathrm{d}} / \delta \varepsilon_{\mathrm{v}}$. In the latter, the yield point identified previously from Fig. 10 is plotted with a bold vertical line. The ratio of the incremental strains gives an indication of the evolution of anisotropy after the onset of yield, with some evidence on elastic anisotropy within the yield locus. It is observed, for all the stress paths examined, that the inflection point for the $\delta \varepsilon_{\mathrm{d}} / \delta \varepsilon_{\mathrm{v}}$ curve broadly coincides with the onset of yield. Fig. 12 indicates that the spread and magnitude of the incremental strains is much larger than the total strain response would indicate. The correspondence between the stress ratio and the ratio, $\delta \varepsilon_{\mathrm{d}} / \delta \varepsilon_{\mathrm{v}}$, is more pronounced than for the total strains, $\varepsilon_{\mathrm{d}} / \varepsilon_{\mathrm{v}}$.

The spatial uniformity in the magnitude of the strain increments is largest for the $K_{0}$ stress path, as is to be expected for the stress path that continues the stress history that the sample has experienced in its formation, and hence the mode of deformation that the material would have experienced during formation (Fig. 12(b)). In addition, at the end of the $K_{0}$ and pseudo-isotropic tests, the final ratio for $\delta \varepsilon_{\mathrm{d}} / \delta \varepsilon_{\mathrm{v}}$ is closer to the applied $q / p^{\prime}$ at boundary level, compared to the highly deviatoric stress path. In contrast to the $K_{0}$ test, the highly deviatoric test at $\eta=0 \cdot 9$, plotted in Fig. 12(a), shows the largest magnitudes for the incremental deviatoric strain. The rate of change of $\delta \varepsilon_{\mathrm{d}} / \delta \varepsilon_{\mathrm{v}}$ significantly slows down post-yield, before stabilising at a value that is substantially larger than $q / p^{\prime}$. Finally, the pseudo-isotropic test shows smaller deviatoric strains than the other two tests, which is commensurate with the pseudo-isotropic loading path. The spread in values for the volumetric strain is largest for this test, and for the deviatoric strain the spread is still larger than that for the $K_{0}$ test. A clear change in trend in the rate of change of $\delta \varepsilon_{\mathrm{d}} / \delta \varepsilon_{\mathrm{v}}$ is observed after yield, where the magnitude of the increment in volumetric strains reduces more slowly than the deviatoric strains.

The evolution of the principal strain direction is used as an additional measure of the spatial heterogeneity of the material distortion. During compressive loading in triaxial conditions the direction of the major principal stress is commonly assumed to be constant and vertical. Fig. 13 shows the deviation of the Euler angle from the vertical direction during the test for the three stress paths. This is a relative measure, where a small magnitude in deviation indicates negligible rotation of the principal strain direction during loading. The results show that, even though initially the principal strain axis deviates, locally in the specimen, from the principal (externally applied) stress axis (the vertical axis), the strain and stress axes start to align at large magnitude of total strain. The latter is observed for all loading paths.

\section{COMPARISON OF STRAIN FIELDS DERIVED FROM DVC TO EXTERNAL MEASUREMENTS}

A large part of this work relates to strain fields calculated from the displacement fields from DVC. Therefore, it is prudent to compare the strains derived by way of DVC to the complementary external measurements. Fig. 14 presents a comparison of the axial strain $\left(\varepsilon_{\mathrm{a}}=\delta l / L_{0}\right)$, for a loading path in highly deviatoric compression with $\eta=0 \cdot 9$. The three different methods used to determine the axial shortening of the sample are

(a) the median value of vertical displacements of all the grid points near the top of the pedestal as analysed using DVC

(b) external (outside the cell) measurements of the change in sample height using a linear variable differential (LVDT) transducer

(c) extracting the axial shortening from the sample contour of the segmented 3D tomographic image and measuring the change in sample length.

The DVC results deviate somewhat from the other two measurement methods. This deviation is most likely due to the fact that it was difficult to obtain reliable measurements on the interface between the sample and the pedestal at very large deformations, because of the reduced number of correlated points.

A similar comparison has been made in terms of the volumetric strain in Fig. 15 for the same test $(\eta=0 \cdot 9)$. This time the following comparison is made.

(a) All values of volumetric strain from the DVC through the measurement volume are combined in a single representative mean value. The arithmetic and the geometrical mean, as well as the median value of local strain for all the nodes on the grid, are plotted.

(b) The volume change of the back-pressure pump, connected to the pore-water volume, is used to calculate the volumetric change of the sample (neglecting deformation of the grains). Values are taken after the back-pressure reaches the in situ pressure target and is kept constant.

(c) Extracting the volumetric strain from the sample contour of the segmented 3D tomographic image using: $\varepsilon_{\mathrm{v}}=1-\left[v(\right.$ voxels $) / V_{0}($ voxels $\left.)\right]$. 

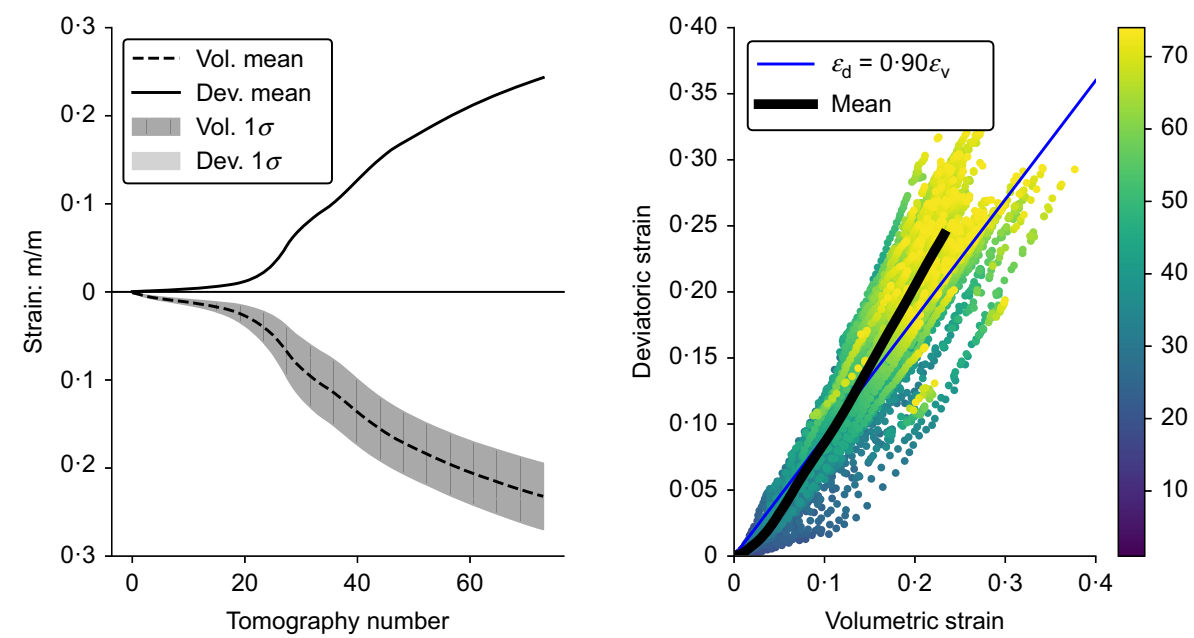

(a)
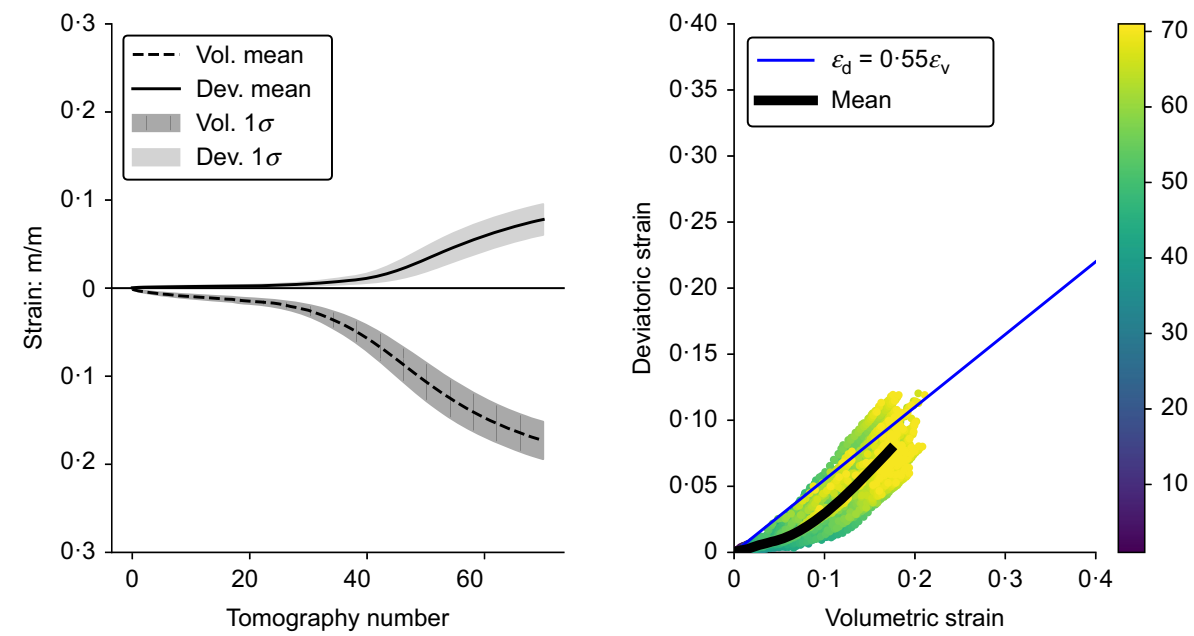

(b)
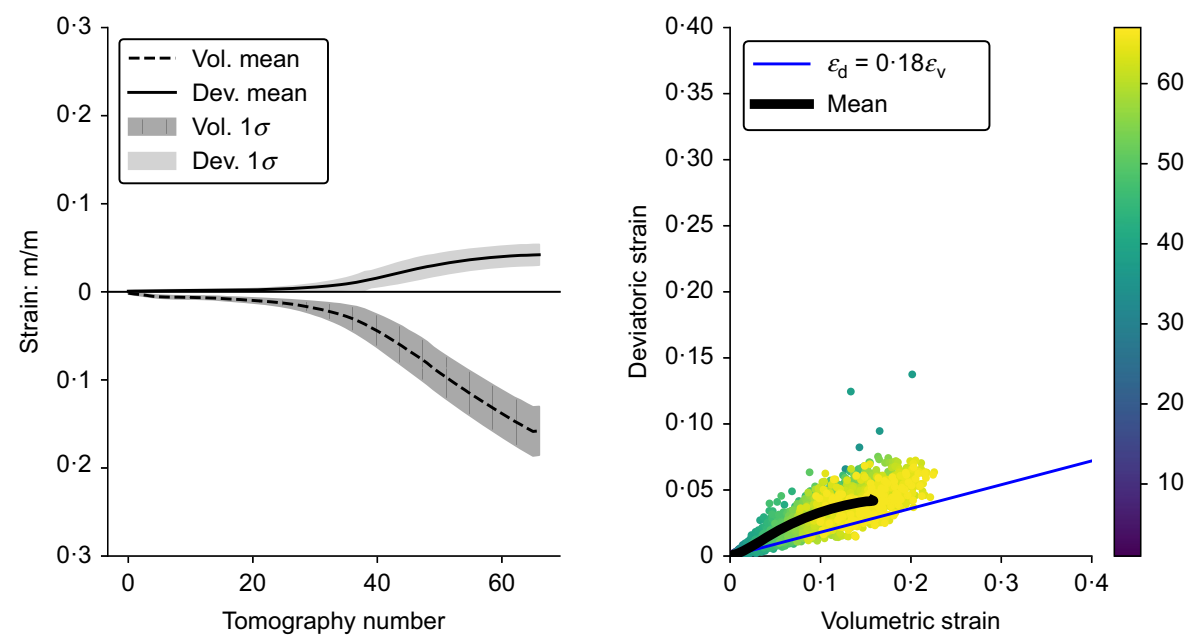

(c)

Fig. 11. Total strains and total strain ratio for the three selected stress paths. On the left the mean and the standard deviation of the deviatoric ('Dev.') and volumetric ('Vol.') strain is plotted together with the scale factor of the initial registration. On the right, the colourmap is used to indicate the tomography number of the plot

The mean values of local strain from the DVC deviate from the volume contour measurements for strains larger than $10 \%$. The volume of drained water in the back-pressure pump underestimates the volume change of the specimen. This finding results from the sensitivity of the back volume measurements to air inclusions for the small volume changes measured for the case of a miniature sample. The volume contour measurements are to be considered the most reliable measurement, as this minimises the uncertainty of measurements.

Despite the different origin and spatial scale of the strain data retrieved from the tomography data (global contour and DVC), 

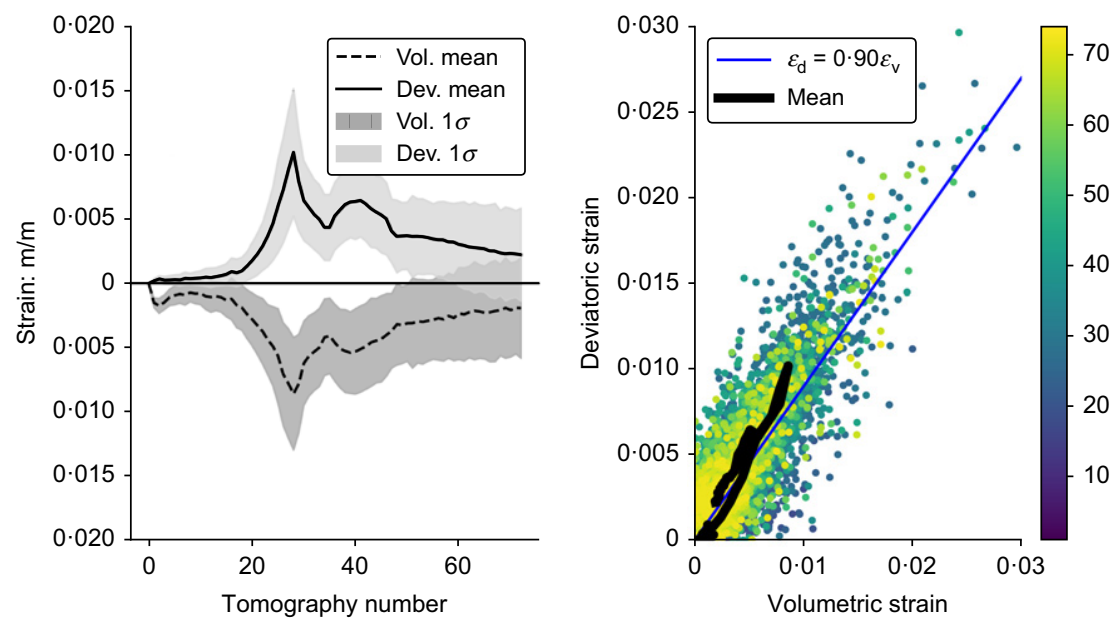

(a)
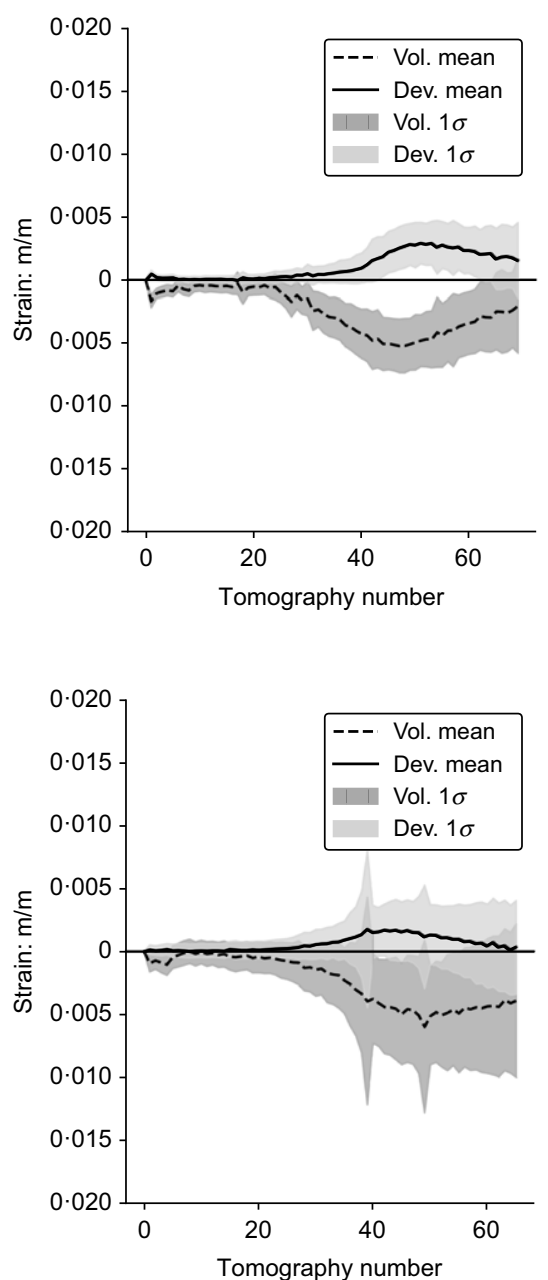

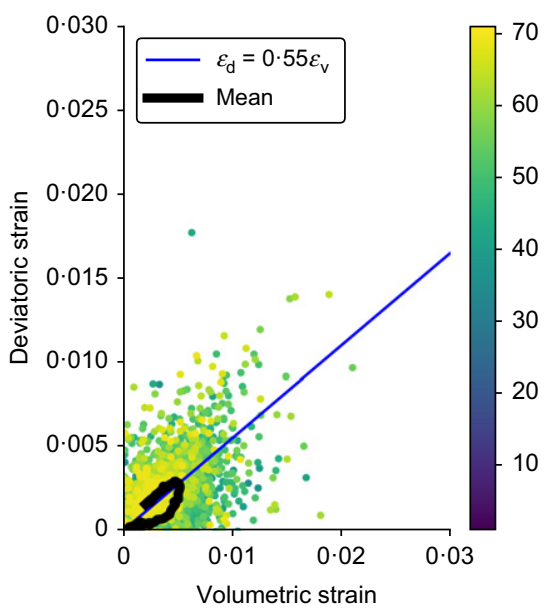

(b)

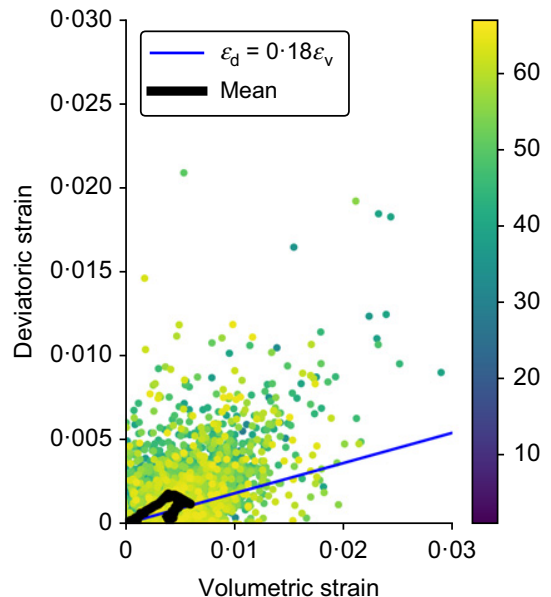

(c)
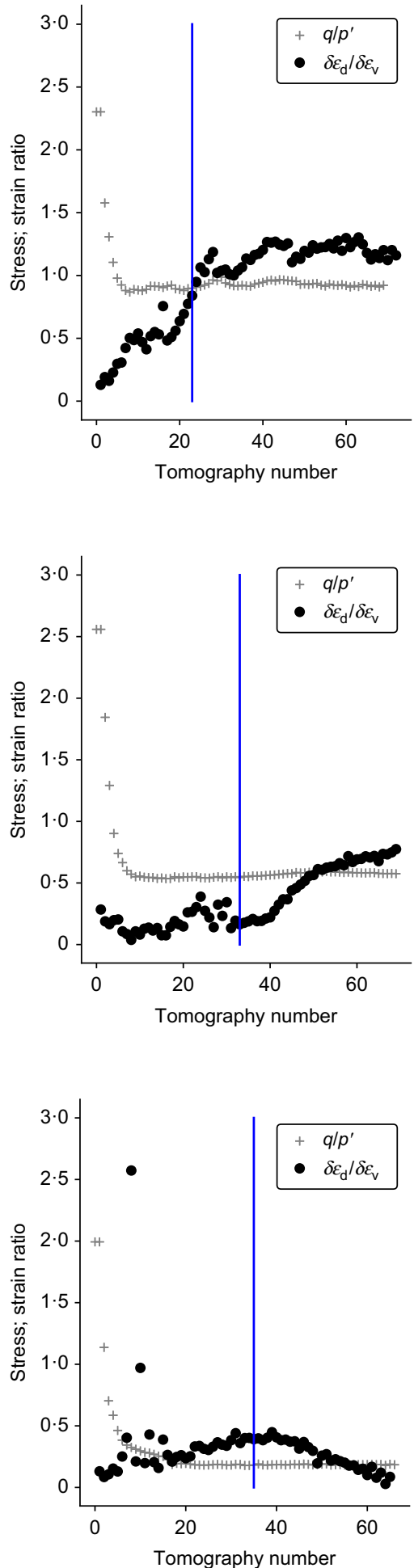

Fig. 12. Incremental strains and incremental strain ratio for the three selected stress paths. On the left, the mean and the standard deviation of the deviatoric ('Dev.') and volumetric ('Vol.') strain is plotted together with the scale factor of the initial registration. In the middle, the colourmap is used to indicate the tomography number of the plot. On the right, the incremental strain ratio is linked to the stress ratio and the bold vertical line corresponds to the yield point

the mean value of the DVC strain fields appears to correlate well with the global volumetric strain, at least for the drained loading paths in triaxial conditions reported herein. The good correlation between DVC strain fields and external data supports the data gathered during drained element level probing of the constitutive behaviour of clay for which there were no 3D deformation data available (e.g. Al-Tabbaa \& Wood, 1989; Wheeler et al., 2003; Karstunen \& Koskinen,
2008). Since there is no distinct difference between the various definitions for the mean value of the volume strain, the arithmetic mean has been used throughout the paper.

\section{CONCLUSIONS}

A new miniature triaxial apparatus for advanced stress path testing of soft clays that is suitable for XCT has been 


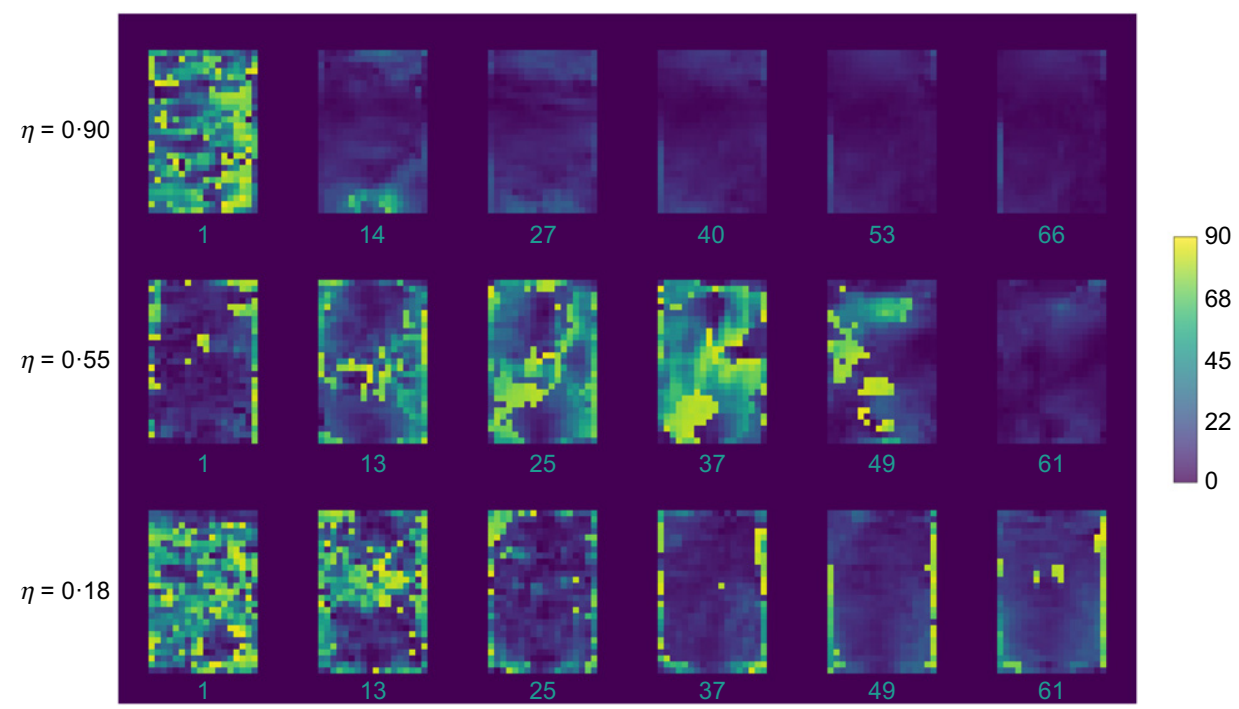

Fig. 13. Euler angle deviation (degrees) of the major principal eigenvector from the vertical axis

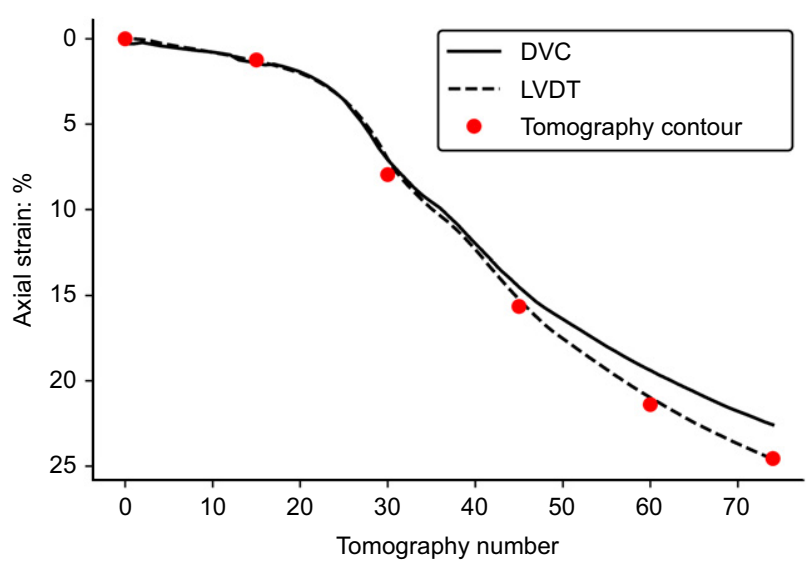

Fig. 14. Comparison of axial strain measurements by various experimental methods: from the displacements calculated near the pedestal by the DVC, external measurements from the LVDT transducer and from the volume contour of the sample by a segmented 3D image

developed. The design incorporates features to facilitate testing at low (effective) stress level, such as the paraffin method, which circumvents the need for a membrane, and a sample mounting procedure that minimises disturbance. This unique combination of XCT and DVC with drained probing in triaxial space gives new insight into the mesoscale deformation mechanisms in natural sensitive clay.

For the drained stress paths tested - namely, at stress ratio $\eta=0 \cdot 18, \eta=0.55$ and $\eta=0 \cdot 9-$ the 3D deformation fields from the DVC are relatively uniform. This implies that the mean value of the DVC strains compares well with independent measurements of change of shape at the boundary of the sample (axial shortening and volume change). In the absence of failure, this mean value for the deviatoric and volumetric strain components describes the global change even for the stress path with some evidence of strain localisation. As expected, the spatial uniformity in the magnitude of the strain increments is largest for the $K_{0}$ loading path with stress ratio $\eta=0 \cdot 55$, followed by the pseudo-isotropic test with $\eta=0 \cdot 18$, whereas the highly deviatoric test at $\eta=0.9$ had the largest spread. This finding is corroborated by the spatial distribution of the principal strain rotations where changes emerge at the mesoscale level $\mathrm{O}\left(0 \cdot 1 \mathrm{~mm}^{3}\right)$.

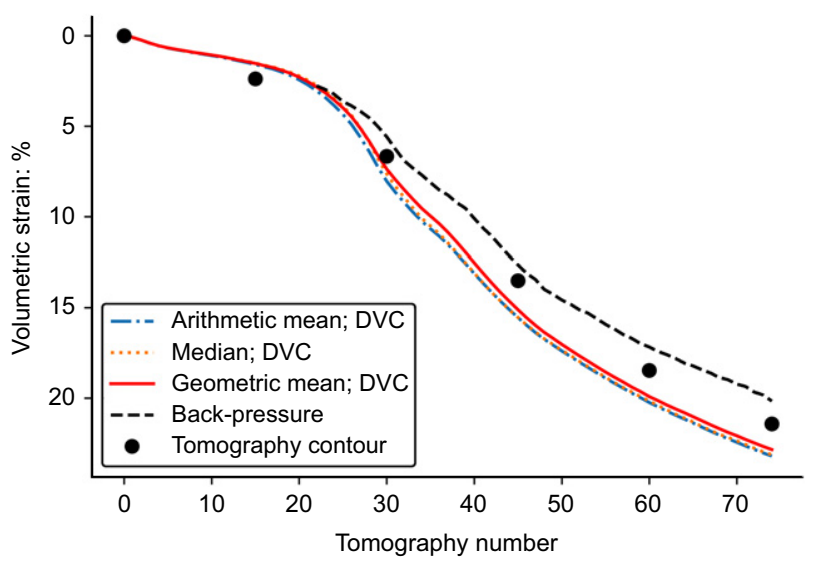

Fig. 15. Comparison of volumetric strain measurements by various experimental methods and statistical means: arithmetic and geometrical mean and median of the strain fields obtained from DVC, external measurements from volume change of the back-pressure pump and from the outside contour of the sample in a segmented 3D image

It has been shown that the stress ratio applied at the boundary level dictates the ratio of total deviatoric and total volumetric strain to a large extent. The ratio of the incremental deviatoric and the incremental volumetric strain, exhibits distinct trends for the load steps before and after the yield point identified in $p^{\prime}-\varepsilon_{\mathrm{V}}$ space. Asymptotic values for this ratio stabilise at different limiting values approaching $\eta$ for the $K_{0}$ and pseudo-isotropic loading path.

\section{DATA AVAILABILITY STATEMENT}

Some or all data used are available from the corresponding author by request.

\section{ACKNOWLEDGEMENTS}

The financial support from the Swedish Research Council (Vetenskapsrådet) under grant no. 491401, FORMAS under grant no. 2016-01070 and Trafikverket in the framework Branschsamverkan i Grunden are gratefully acknowledged. Author G.B. acknowledges the financial support towards the experimental campaign from Chalmersska forskningsfonden. 
NOTATION

$\boldsymbol{F}$ transformation gradient tensor

$L_{0} \quad$ initial sample length (mm)

$M$ critical state line

$p^{\prime}$ mean effective stress $(\mathrm{kPa})$

$q$ deviatoric stress $(\mathrm{kPa})$

$\boldsymbol{R}$ rotation tensor

$S_{\mathrm{t}}$ sensitivity

$\boldsymbol{U}$ stretch tensor

$\boldsymbol{u}$ linear displacement vector

$w_{1}$ liquid limit (\%)

$w_{\mathrm{n}}$ natural water content $(\%)$

$w_{\mathrm{p}}$ plastic limit $(\%)$

$\boldsymbol{x}$ position vector

$\delta_{1} \quad$ length reduction $(\mathrm{mm})$

$\varepsilon_{\mathrm{a}}$ axial strain

$\varepsilon_{\mathrm{d}} \quad$ deviatoric strain

$\varepsilon_{\mathrm{v}} \quad$ volumetric strain

$\eta$ ratio of deviatoric to mean effective stress

$\mu$ linear attenuation coefficient

$\rho$ unit density $\left(\mathrm{t} / \mathrm{m}^{3}\right)$

$\sigma_{1}^{\prime}$ major principal effective stress $(\mathrm{kPa})$

$\sigma_{3}^{\prime} \quad$ minor principal effective stress $(\mathrm{kPa})$

$\tau_{\mathrm{fu}} \quad$ undrained shear strength from fall cone test correlation $(\mathrm{kPa})$

$\Phi$ linear deformation function

\section{REFERENCES}

Alshibli, K. \& Hasan, A. (2008). Spatial variation of void ratio and shear band thickness in sand using X-ray computed tomography. Géotechnique 58, No. 4, 249-257, https://doi.org/10.1680/ geot.2008.58.4.249.

Al-Tabbaa, A. \& Wood, D. (1989). An experimentally based bubble model for clay. In Numerical models in geomechanics, NUMOG III (eds S. Pietrusczak and G. N. Pande), pp. 91-99. London, UK: Elsevier Applied Science.

Amorosi, A. \& Rampello, S. (2007). An experimental investigation into the mechanical behaviour of a structured stiff clay. Géotechnique 57, No. 2, 153-166, https://doi.org/10.1680/geot. 2007.57.2.153.

Anandarajah, A., Kuganenthira, N. \& Zhao, D. (1996). Variation of fabric anisotropy of kaolinite in triaxial loading. J. Geotech. Engng 122, No. 8, 633-640.

Andó, E., Viggiani, S. H. G., Desrues, D. \& Bésuelle, P. (2012). Grain-scale experimental investigation of localised deformation in sand: a discrete particle tracking approach. Acta Geotech. 7, No. 1, 1-13.

Arthur, J. (1962). Strains and lateral force in sands. PhD thesis, University of Cambridge, Cambridge, UK.

Birmpilis, G., Dijkstra, J., Tudisco, E. \& Hal, S. A. (2017). In situ study of deformation mechanisms of soft clay using X-ray computed tomography and digital volumetric correlation. 3rd international conference on tomography of materials and structures, ICTMS2017, Lund, Sweden.

Birmpilis, G., Hall, S., Lages, S. and Dijkstra, J. (2019). Monitoring of the nano-structure response of natural clay under mechanical perturbation using small angle X-ray scattering and digital image correlation. Acta Geotech. 14, No. 6, 1965-1975, https://doi.org/10.1007/s11440-019-00832-8.

Bishop, A. \& Wesley, L. (1975). A hydraulic triaxial apparatus for controlled stress path testing. Géotechnique 25, No. 4, 657-670, https://doi.org/10.1680/geot.1975.25.4.657.

Brand, E. and Brenner, R. (1981). Soft clay engineering, pp. 485-491. Amsterdam, the Netherlands: Elsevier Science.

Burland, J. (1990). On the compressibility and shear strength of natural clays. Géotechnique 40, No. 3, 329-378, https://doi.org/ 10.1680/geot.1990.40.3.329.

Cabrera, J. \& Smalley, I. (1973). Quickclays as products of glacial action: a new approach to their nature, geology, distribution and geotechnical properties. Engng Geol. 7, No. 2, 115-133.

Cotecchia, F. \& Chandler, R. (1997). The influence of structure on the pre-failure behaviour of natural clay. Géotechnique 47, No. 3, 523-544, https://doi.org/10.1680/geot.1997.47.3.523.

Cotecchia, F., Guglielmi, S., Cafaro, F. \& Gens, A. (2019). Characterisation of the multi-scale fabric features of high plasticity clays. Géotechnique Lett. 9, No. 4, 361-368, https://doi.org/10.1680/jgele.18.00230.

Deirieh, A. (2016). From clay slurries to mudrocks: a cryo-SEM investigation of the development of the porosity and microstructure. PhD thesis, Massachussets Institute of Technology, Cambridge, MA, USA.

Deirieh, A., Chang, I. Y., Whittaker, M. L., Weigand, S., Keane, D., Rix, J., Germaine, J. T., Joester, D. \& Flemings, P. B. (2018). Particle arrangements in clay slurries: the case against the honeycomb structure. Appl. Clay Sci. 152, 166-172.

Delage, P. \& Lefebvre, G. (1984). Study of the structure of a sensitive Champlain clay and of its evolution during consolidation. Can. Geotech. J. 21, No. 1, 21-35.

Delage, P. \& Pellerin, F. M. (1984). Influence de la lyophilisation sur la structure d'une argile sensible du Québec. Clay Miner. 19, No. 2, 151-160 (in French).

Desrues, J., Chambon, R., Mokni, M. \& Mazerollet, F. (1996). Void ratio evolution inside shear bands in triaxial sand specimens studied by computed tomography. Géotechnique 46, No. 3, 529-546, https://doi.org/10.1680/geot.1996.46.3.529.

Diamond, S. (1970). Microstructure and pore structure of impact compacted clays. Clays Clay Miner. 19, No. 4, 239-249.

Hall, S. A., Bornert, M., Desrues, J., Pannier, Y., Lenoir, N., Viggiani, G. \& Bésuelle, P. (2010). Discrete and continuum analysis of localised deformation in sand using X-ray CT and volumetric digital image correlation. Géotechnique 60, No. 5, 315-322, https://doi.org/10.1680/geot.2010.60.5.315.

Hattab, M. \& Fleureau, J. M. (2010). Experimental study of kaolin particle orientation mechanism. Géotechnique 60, No. 5, 323-331, https://doi.org/10.1680/geot.2010.60.5.323.

Hattab, M., Hammad, T., Fleureau, J. M. \& Hicher, P. Y. (2013). Behaviour of a sensitive marine sediment: microstructural investigation. Géotechnique 63, No. 1, 71-84, https://doi.org/ 10.1680/geot.10.P.104.

Hattab, M., Hammad, T. \& Fleureau, J. M. (2015). Internal friction angle variation in a kaolin/montmorillonite clay mix and microstructural identification. Géotechnique 65, No. 1, 1-11, https://doi.org/10.1680/geot.13.P.081.

Hicher, P., Wahuydi, H. \& Tessier, D. (2000). Microstructural analysis of inherent and induced anisotropy in clay. Mech. Cohes.-Frict. Mater 5, No. 5, 341-371.

Hild, F. \& Roux, S. (2012). Comparison of local and global approaches to digital image correlation. Expl Mech. 52, No. 9, 1503-1519.

Iversen, K. \& Moum, J. (1974). The paraffin method - triaxial testing without a rubber membrane. Géotechnique 24, No. 4, 665-670, https://doi.org/10.1680/geot.1974.24.4.665.

Karlsson, M., Emdal, A. \& Dijkstra, J. (2016). Consequences of sample disturbance when predicting long-term settlements in soft clay. Can. Geotech. J. 53, No. 12, 1965-1977, https://doi.org/10.1139/cgj-2016-0129.

Karstunen, M. \& Koskinen, M. (2008). Plastic anisotropy of soft reconstituted clays. Can. Geotech. J. 45, No. 3, 314-328, https://doi.org/10.1139/T07-073.

Kirkpatrick, W. \& Belshaw, D. (1968). On the interpretation of the triaxial test. Géotechnique 18, No. 3, 336-350, https://doi.org/ 10.1680/geot.1968.18.3.336.

Lapierre, C., Leroueil, S. \& Locat, J. (1990). Mercury intrusion and permeability of Louiseville clay. Can. Geotech. J. 27, No. 6, 761-773.

Lenoir, N., Bornert, M., Desrues, J., Bésuelle, P. \& Viggiani, G. (2007). Volumetric digital image correlation applied to X-ray microtomography images from triaxial compression tests on argillaceous rock. Strain 43, No. 3, 193-205.

Leroueil, S. \& Vaughan, P. (1990). The general and congruent effects of structure in natural soils and weak rocks. Géotechnique 40, No. 3, 467-488, https://doi.org/10.1680/geot. 1990.40.3.467.

Li, Y., Dijkstra, J. \& Karstunen, M. (2018). Thermomechanical creep in sensitive clays. J. Geotech. Geoenviron. Engng 144, No. 11, 04018085.

Lucas, B. D. \& Kanade, T. (1981). An iterative image registration technique with an application to stereo vision. In Proceedings of the 7th international joint conference on artificial intelligence: IJCAI'81 (ed. A. Drinan), vol. 2, pp. 674-679. San Francisco, CA, USA: Morgan Kaufmann. 
Lunne, T., Berre, T. \& Strandvik, S. (1997). Sample disturbance effects in soft low plastic Norwegian clay. In Proceedings of the conference on recent developments in soil and pavement mechanics (ed. M. Almeida), pp. 81-102. Rotterdam, the Netherlands: Balkema.

Ma, C. \& Eggleton, R. A. (1999). Cation exchange capacity of kaolinite. Clays Clay Miner. 47, No. 2, 147-180.

Martin, R. T. \& Ladd, C. C. (1975). Fabric of consolidated kaolinite. Clays Clay Miner. 23, No. 1, 17-25.

Matsushima, T., Uesugi, K., Nakano, T. \& Tsuchiyama, A. (2010). Visualization of grain motion inside a triaxial specimen by micro $X$-ray CT at SPring-8. In Advances in X-ray tomography for geomaterials (eds J. Desrues, G. Viggiani and P. Bésuelle), pp. 255-261. London, UK: John Wiley \& Sons, Ltd.

Menaceur, H., Delage, P., Tang, A. M. \& Talandier, J. (2016). The status of water in swelling shales: an insight from the water retention properties of the Callovo-Oxfordian Claystone. Rock Mech. Rock Engng 49, No. 12, 4571-4586.

Mitaritonna, G., Amorosi, A. \& Cotecchia, F. (2014). Experimental investigation of the evolution of elastic stiffness anisotropy in a clayey soil. Géotechnique 64, No. 6, 463-475, https://doi.org/ 10.1680/geot.13.P.191.

Pedrotti, M. \& Tarantino, A. (2018). An experimental investigation into the micromechanics of non-active clays. Géotechnique $\mathbf{6 8}$, No. 8, 666-683, https://doi.org/10.1680/jgeot.16.P.245.

Pusch, R. (1966). Quick-clay microstructure. Engng Geol. 1, No. 6, 433-443.

Quigley, R. \& Thompson, C. (1966). The fabric of anisotropically consolidated sensitive marine clay. Can. Geotech. J. 3, No. 2, 61-73.

Roscoe, K., Arthur, J. \& James, R. (1963). The determination of strains in soils by an X-ray method. Civ. Engng Publ. Wks Rev. 58, 873-876 and 1009-1012.
Smith, P., Jardine, R. \& Hight, D. (1992). The yielding of Bothkennar clay. Géotechnique 58, No. 3, 199-113, https://doi. org/10.1680/geot.1992.42.2.257.

Stamati, O., Andó, E., Roubin, E., Cailletaud, R., Wiebicke, M., Pinzon, G., Couture, C., Hurley, R. C., Caulk, R., Caillerie, D., Matsushima, T., Bésuelle, P., Bertoni, F., Arnaud, T., Ortega Laborin, A., Rorato, R., Sun, Y., Tengattini, A., Okubadejo, O., Colliat, J. B., Saadatfar, M., Garcia, F. E., Papazoglou, C., Vego, I., Brisard, S., Dijkstra, J. \& Birmpilis, G. (2020). Spam: software for practical analysis of materials. J. Open Source Softw. 5, No. 51, 2286

Stavropoulou, E., Andò, E., Roubin, E., Lenoir, N., Tengattini, A., Briffaut, M. \& Bésuelle, P. (2020). Dynamics of water absorption in Callovo-Oxfordian claystone revealed with multimodal $\mathrm{X}$-ray and neutron tomography. Front. Earth Sci. 8, No. 6, https://doi.org/10.3389/feart.2020.00006.

Tanaka, H. \& Locat, J. (1999). A microstructural investigation of Osaka Bay clay: the impact of microfossils on its mechanical behaviour. Can. Geotech. J. 36, No. 3, 493-508.

Tudisco, E., Jailin, C., Mendoza, A., Tengattini, A., Andò, E., Hall, S., Viggiani, G., Hild, F. \& Roux, S. (2017). An extension of digital volume correlation for multimodality image registration. Meas. Sci. Technol. 28, No. 9, 095401, https://doi.org/ 10.1088/1361-6501/aa7b48.

Viggiani, G., Andò, E., Takano, D. \& Santamarina, J. (2015). Laboratory X-ray tomography: a valuable experimental tool for revealing processes in soils. Geotech. Test. J. 38, No. 1, 61-71.

Wheeler, S., Häätänen, A., Karstunen, M. \& Lojander, M. (2003). An anisotropic elastoplastic model for soft clays. Can. Geotech. J. 40, No. 2, 403-418, https://doi.org/10.1139/ t02-119. 